\title{
Women Participation in Farmer Managed 134 Natural Regeneration for Climate Resilience: Laisamis, Marsabit County, Kenya
}

\author{
Irene Ojuok and Tharcisse Ndayizigiye
}

\section{Contents}

Introduction

Findings and Recommendations

To Identify Potential Risks Associated with Climate Change and Land Degradation

Facing the Communities in Laisamis (Mention the Key Threats, Who Is Most at

Risk, Why)

Assess the Opportunities FMNR Has in Increasing the Resilience of the Communities to these Risks (Define FMNR, Its Key Benefits from an Environmental, Economic,

Social View, etc.)

What Are the Roles of Men and Women in Uptake of FMNR

What Drives Women to Participate in or to Adopt FMNR

Key Barriers Affecting Women Participation in FMNR ..

Recommendations for Enhancing Women Participation in FMNR Uptake

Conclusion

References

This chapter was previously published non-open access with exclusive rights reserved by the Publisher. It has been changed retrospectively to open access under a CC BY 4.0 license and the copyright holder is "The Author(s)". For further details, please see the license information at the end of the chapter.

I. Ojuok $(\triangle)$

National Technical specialist Environment and Climate Change, World Vision Kenya, Nairobi, Kenya

e-mail: Irene_ojuok@wvi.org; barrackawino@yahoo.com

T. Ndayizigiye

SMHI/Swedish Meteorological and Hydrological Institute, Nairobi, Kenya

e-mail: Tharcisse.Ndayizigiye@smhi.se 


\section{Abstract}

Despite the fact that land degradation is both natural and human-induced, it is proven that human activities pose greatest threat and these include unsustainable land management practices such as destruction of natural vegetation, overcultivation, overgrazing, poor land husbandry, and excessive forest conversion. Other than reduced productivity, land degradation also leads to socioeconomic problems such as food insecurity, insufficient water, and regular loss of livestock which exacerbate poverty, conflicts, and gender inequalities that negatively impact mostly women and children especially the rural population. Increased efforts by governments, donors, and partners toward reversing land degradation through community-led, innovative, and effective approaches therefore remain to be crucial today than never before!

Farmer-managed natural regeneration (FMNR) is a proven sustainable land management technology to restore degraded wasteland and improve depleted farmland. This approach has been tested across Africa with high success rates. In spite of the huge local, regional, and global efforts plus investments put on promoting FMNR across different landscapes among vulnerable communities for climate resilience, the implementation of such projects has not been as successful as intended due to slow women uptake and participation in the approach. In order of ensuring women who are mostly at highest risk to impacts of climate change enjoy the multiple benefits that come along with FMNR, the success rate for uptake of FMNR especially among women need to be enhanced.

This chapter seeks to explore drivers and barriers of women participation in uptake of FMNR for climate resilience. Findings will be shared from a 3-year project dubbed Integrated Management of Natural Resources for Resilience in ASALs and a Food and Nutrition project both in Laisamis, Marsabit County, Kenya. The program interventions on natural resource management for livelihoods seek to integrate gender and conflict prevention and prioritize sustainable, market-based solutions to address the persistent challenges. The chapter discusses findings, successes, and lessons learned from the actions and the requirement to position women as vulnerable groups at the center of initiatives designed to address the climate change crisis. The outcome of this chapter will enhance gender-responsive FMNR programing through awareness creation, effective organization/project designs, strategies, and plans together with advocacy and policy influence. Limitations of the study and main recommendations for future programing in similar contexts are also shared.

\section{Keywords}

Gender · Mainstreaming $\cdot$ Women $\cdot$ Participation $\cdot$ FMNR Uptake $\cdot$ Climate resilience $\cdot$ Marsabit $\cdot$ Kenya 


\section{Introduction}

Climate change is so far viewed as one of the greatest challenges facing humanity manifested in the form of variation in amount and distribution of precipitation, ocean salinity, wind patterns, and aspects of extreme weather leading to droughts and flooding, among others. These changes threaten community livelihoods, economy, ecosystems, and social cohesion. Africa is particularly viewed to bear the brunt of the climate change threats mainly due to its poor economic development and low institutional capacity. Vulnerable communities especially women and children within the continent are facing the highest pressure following conspicuous threats like decline in crop production, livestock deaths due to droughts, malnutrition, resource-based conflicts, and migration (Fig. 1).

Globally, women are underrepresented in natural resource management (NRM) and peace building, and they are also disproportionately affected by poor NRM because of gendered power relations that deny women access to resources such as land. Women especially in the rural areas are primary providers of water, food, and energy at the household level and therefore bear heaviest impact of poor resource management. In many of the ASALS areas of Kenya, the frequency and magnitude of droughts, floods, and famine have increased significantly in the recent past. This has impacted nega-

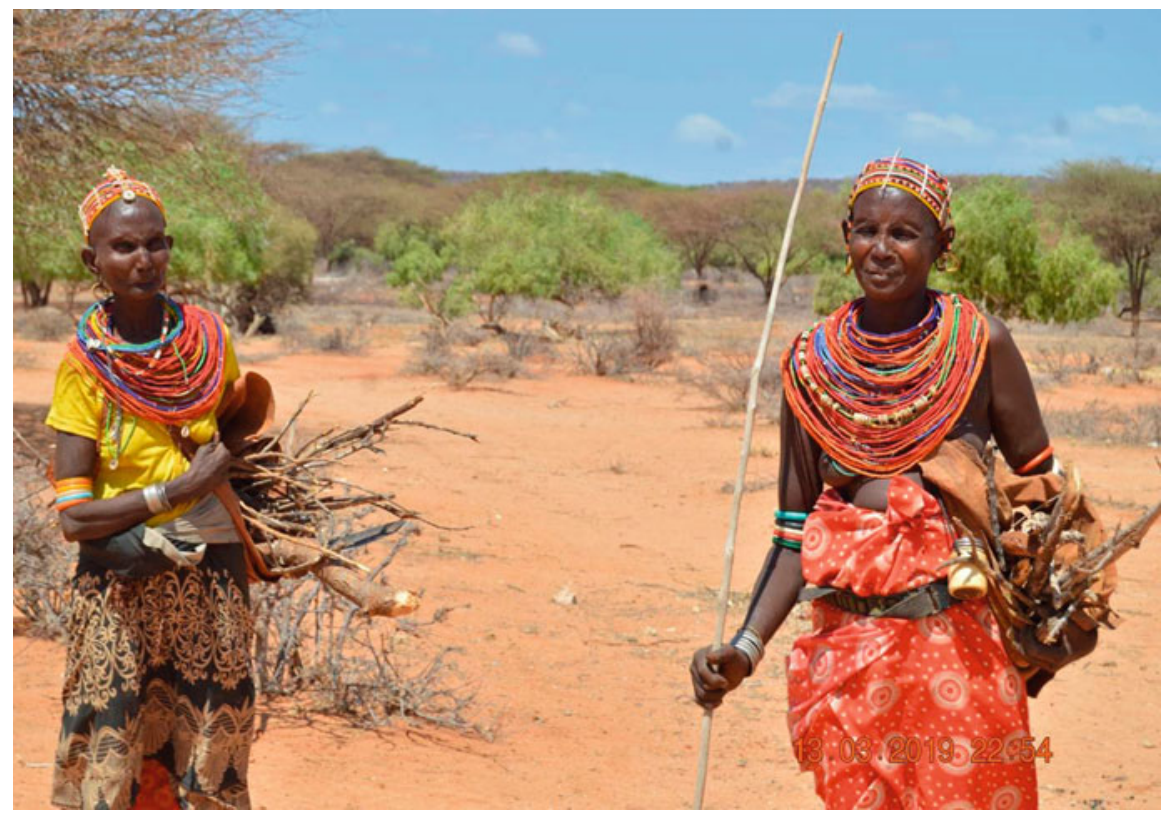

Fig. 1 Women in search of firewood, Marsabit, Kenya, February 2019. (Photo: Irene Ojuok, World Vision Kenya) 
tively on the pastoralist communities and especially the women whose vulnerability to the impacts of climate change is necessitated by their roles at household level as caregivers. In Kenya, tens of thousands of hectares of farmlands have become so degraded that they no longer produce adequate or regular crops or pasture for livestock. Historically, there has been a male bias in development program research, planning, and implementation activities, which ignore women's role in dryland development and the challenges that they face. Moreover, women generally do not participate in the decisionmaking processes in the community. Increasingly, women and youth are usually the most marginalized groups often suffering first in situations of severe food and water shortage. They carry the largest burden of searching for fuelwood, pasture, cooking food, and gathering wild fruits, among others. Poor management of natural resources can lead to overuse and degradation, desertification, deforestation, soil erosion, declining water tables, and other effects that can threaten livelihoods and peace. Sometimes, this leads to conflict at household or even between communities. Forest goods and services are largely public in nature and therefore depend to a large extent on public funding. However, prioritization of public investment and incentives to the private sector for forestry development has been low partly as a result of low valuation of forestry goods and services leading to very slow growth of the sector. This has sometimes accounted for the increased utilization of the forest resources beyond its capacity to sustainably be replenished especially due to the fact that increased population and urbanization are largely dependent on these resources. In forest management, women's traditional roles (e.g., collecting water, growing food, etc.) are particularly crucial in drylands in terms of natural resource management and food security. Men have usually been responsible for decision-making and planning of farming activities especially where land is productive with high economic returns, but with the increasing land degradation, they leave the degraded areas to look for jobs in urban areas, leaving women to assume new roles and responsibilities on the farm. In such a changing context, it is fundamental to be aware of the obstacles hindering full participation of disadvantaged groups, including women in the adverse climate change conditions (Figs. 2 and 3).

Kenya has cited climate change as one of the most serious challenges affecting achievement of its development goals as described under Vision 2030. Toward this end, in 2010, Kenya developed a National Climate Change Response Strategy (NCCRS) followed by the National Climate Change Action Plan (NCCAP) in 2012, which recognized the importance of climate change impacts on the country's development and identifies significant adaptation measures in various sectors of the economy. However, there has been lack of gender-sensitive targets and indicators purposefully set to track progress. There is also need for capacity-building with respect to climate change and its implications for achieving Kenya's gender and development targets. Climate risk management efforts could equally be strengthened by improving understanding of the implications of climate change for Kenyan women and other vulnerable groups, deepening analysis of how to develop and implement adaptation measures that minimize adverse impacts on these groups, and integrating this knowledge into policy and program implementation. Creation of this understanding will likely need to be supported by extensive research and more awareness-raising with policy-makers and experts in this field. 


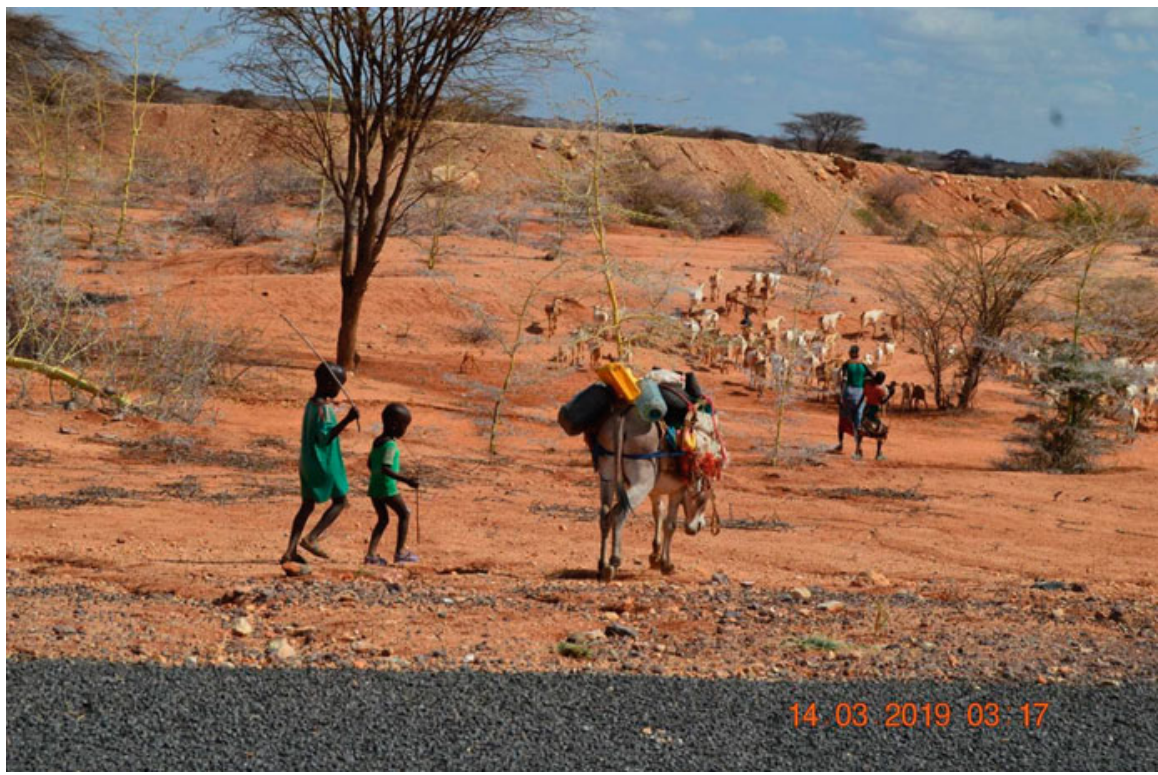

Fig. 2 Displaced family moving to new place for settlement due to drought extreme in Marsabit County. (Photo: Irene Ojuok)

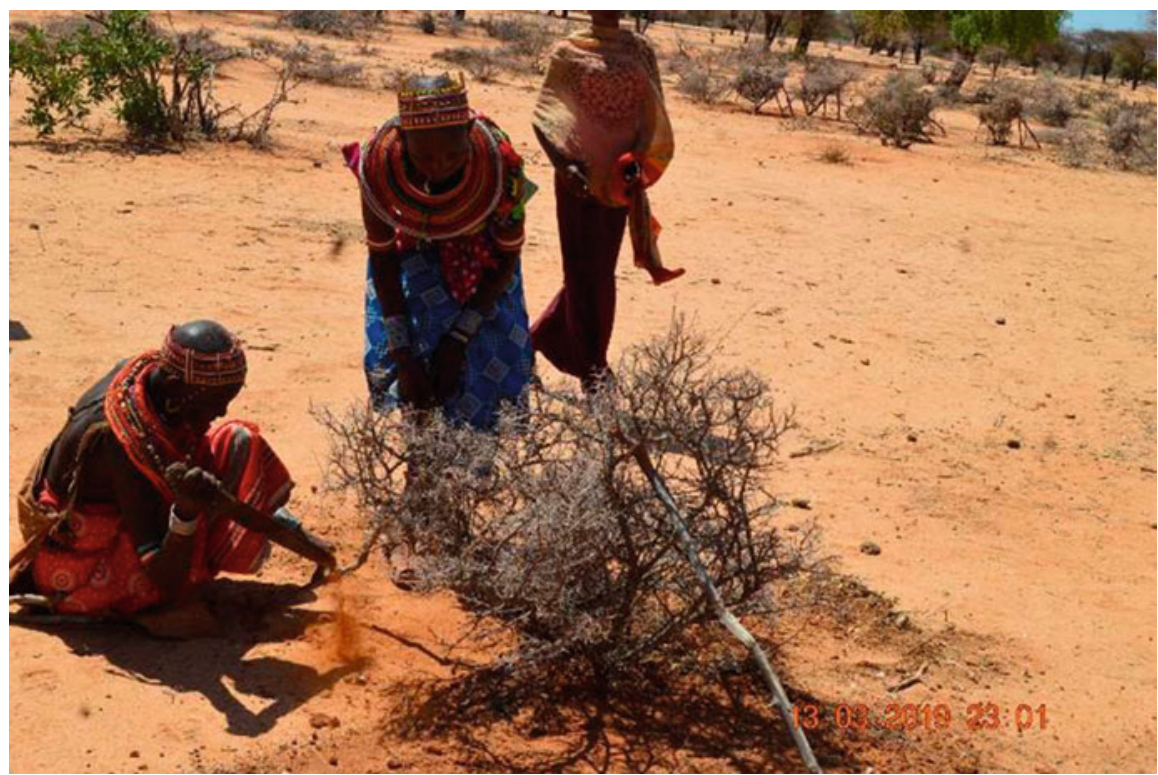

Fig. 3 Women practising FMNR in Laisamis, Marsabit County. (Photo: Irene Ojuok) 
Farmer-managed natural regeneration is a low-cost, sustainable land restoration technique used to combat poverty and hunger among poor subsistence farmers in developing countries by increasing food and timber production and resilience to climate extremes. It involves the systematic regeneration and management of trees and shrubs from tree stumps, roots, and seeds. World Vision has successfully implemented FMNR as a sustainable forest management approach among communities with tremendous uptake by communities especially in ASAL areas due to the sustainable benefits derived from the tree management systems. Among the tree based value chains are like sale of fuelwood, pasture bulking, and beekeeping which are some of the drivers identified that have motivated farmers to increase restoration efforts due to increased returns from wood and non-wood products. The main beneficiaries of this approach are those who depend more on tree resources: farmers, herders, and particularly women and children who harvest wood and non-timber forest products, which are based on documented economic values of FMNR.

There is, however, a need for in-depth analysis and dissemination of findings on the role of women in natural resource management with focus on drivers of women participation on FMNR for increased climate change resilience in ASAL counties of Kenya. In every society, there are marginalized groups, often including women and children, people with disabilities, and minorities. External parties can play a critical role in opening the eyes of all to the benefits of inclusion and in facilitating positive change sensitively hence need for this chapter in the climate adaptation hand book.

The case study for this chapter draws on World Vision that has wealth of experience in implementing FMNR approach which has been successful in different contexts in Kenya over the last 8 years including in semiarid areas. Between 2018 and 2021, World Vision Kenya (WVK) in partnership with Northern Rangeland Trust (NRT) and Stockholm Environment Institute (SEI) will be implementing a project dubbed Integrated Management of Natural Resources for Resilience in ASALs (IMARA). The goal of the project is toward increasing resilience of about 35,000 marginalized households to climate changerelated shocks through diversified livelihoods and improved natural resource management and use in the ASAL Counties of Isiolo, Laikipia, Marsabit, and Samburu through funding from SIDA. The key objectives are as follows: (1) secure livelihoods and strengthened market systems (including for women and youth) that support sustained management of natural resources; (2) sustainable management and rehabilitation of land, forest, and water sources for strengthened ecosystem services; and (3) strengthened governance systems and structures for sustainable NRM at community, county, and national levels. As part of baseline and program intervention mapping, a gender and social inclusion assessment were conducted in the target program area to establish key sociocultural, economic, political, and technological issues that affect participation of women and youth. This is in line with the Swedish Development Cooperation Strategy for Kenya (2016-2020) which includes a focus on "A better environment, limited climate impact and greater resilience to environmental impacts, climate change and natural disasters."

To complement these objectives, the proposed case study will be limited to identifying the key factors that drive or bar women participation in adoption of FMNR approach for climate resilience in Marsabit County. The findings will be used to develop strategies to effectively and meaningfully engage women in all stages of program implementation cycle. The study findings will strive to enhance women, 
girls, boys, and men in the community participate in a process which allows them to express their needs and to decide their own future with a view to their empowerment in sustainable NRM, livelihoods, and governance domains for increased resilience to impacts of climate change.

The study opted social research using qualitative survey approach. The main method was through interviews using focused group discussions (FGD) and key informant interviews (KII). In this process, KII guide and FGD guides were the main tools adopted for use during the research. The sampling was purposive since it was intended to get information from targeted audience with knowledge on natural resource management and FMNR approach. The interviews entailed for ten sets of respondents (three FGD comprising women only, men only, and mixed group of men and women of different age groups, KIIs including two government officers from environment and agriculture departments, woman FMNR champion, youthful male and female practicing FMNR, World Vision staff implementing the project in Marsabit, and a local chief). An interpreter from the local community supported translations during the interviews due to language barriers in some instances. Summary tables based on the study themes were employed for analysis using the QDA Miner Lite version 2.0.6. The analysis results were presented in terms of tables, graphs, and pie charts. Secondary data sources sourced from document review using document review matrix guide aligned with the key study objectives. Observations were conducted during field travels while doing data collection in the villages of Marsabit. Photography was equally used to obtain general status of the landscape encompassing key features, e.g., vegetation and habitat, migrations, human settlement, and human activities, e.g., trade, livestock rearing, land restoration efforts, etc. (Fig. 4).

\section{Findings and Recommendations}

\section{To Identify Potential Risks Associated with Climate Change and Land Degradation Facing the Communities in Laisamis (Mention the Key Threats, Who Is Most at Risk, Why)}

Overall, extreme climatic conditions linked to climate change mostly mentioned by the respondents include severe and prolonged drought, increased flood occurrences (El Niño), extreme heat caused by high temperatures, low and irregular rainfall

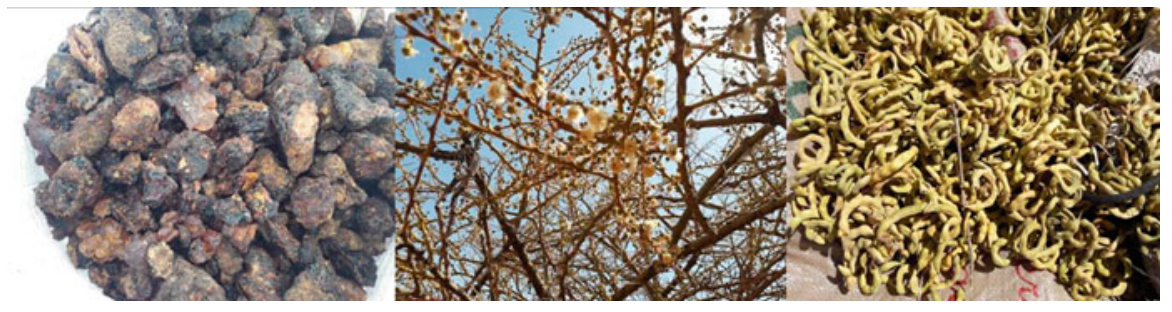

Fig. 4 FMNR benefits - gums and resins, flowers, and seeds used as livestock feed critical in drought season. (Photo: Irene Ojuok) 
patterns, and disease outbreaks, e.g., malaria and diarrhea. In the month of April 2019 (Kenya 2019), seven people were confirmed dead following the outbreak of kala-azar vector (sand fly) disease in Marsabit County mainly in Laisamis subcounty. This insect is most active in humid environments during the warmer months and at night, from dusk to dawn. According to the World Health Organization (WHO) 14 March 2019 report, this disease which mainly affects the poorest people on Earth is linked to environmental changes such as deforestation, building of dams, irrigation schemes, and urbanization. Environmental management hence cited important in reducing or interrupting transmission of this disease (Fig. 5).

Intensified pressure on natural resources is attributed to water scarcity, limited pasture, increased deforestation, limited access to firewood, soil and wind erosion, and along the river beds overharvesting of sand. Risks associated with climate change have also led to loss of livelihoods and food insecurity leading to death or poor health of livestock, low crop yields, increased charcoal burning for sale, and loss of wild fruits and seeds/fodder usually consumed by human and livestock during severe drought. Hunger and malnutrition manifest itself in these cases. Some of the social challenges include displacements/migration; conflict over natural resources; increased crime, e.g., cattle raiding; school dropouts; family breakdown; and poverty. One of the respondents emphasized that during drought "only one out of five children attends schools" hence higher levels of illiteracy in the region. In a men FGD, one respondent expressed threats associated with morans marrying their women since the younger men can offer better living conditions than the older ones.

$91 \%$ of the respondents reported that women and children are the most at risk in these circumstances. The reproductive roles undertaken solely by women were emphasized to increase their vulnerability in negative climate change impacts. For instance, when men migrate in search of pasture, women take up full responsibility

RISKS DUE TO CLIMATE CHANGE \& LAND DEGRADATION.

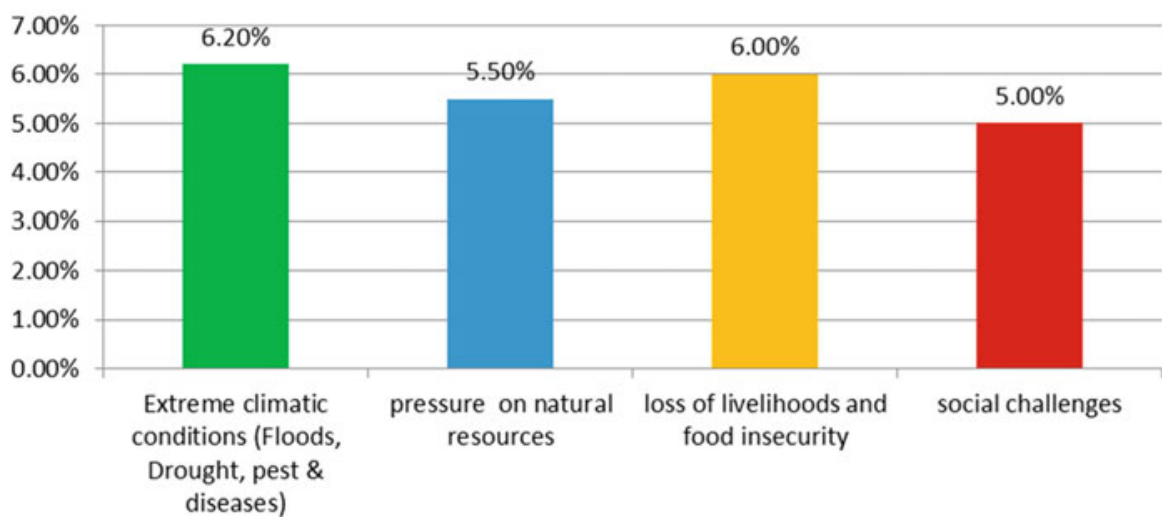

Fig. 5 Analysis of risks associated with climate change 
for households; conflicts due to pressure on natural resources leave women most affected because of their weak levels of defense, and hunger caused by drought deteriorates health of pregnant and lactating mothers including children under five. The men-only FGD confirmed that a woman had been killed in the process of protecting her children when an enemy attacked their household and the man had migrated with large herds in search of pasture. Limitations on decision-making and utilization of valuable resources that can help support them while in need, e.g., livestock, land, and large-scale sale of tree value chains, are mainly men-dominated, and they shared justifications to this. This emphasizes the critical need of enhancing women participation in sustainable natural resource management while exploring the potentials FMNR has in increasing their resilience to climate change (Fig. 6).

\section{Assess the Opportunities FMNR Has in Increasing the Resilience of the Communities to these Risks (Define FMNR, Its Key Benefits from an Environmental, Economic, Social View, etc.)}

The FGDs and KIIs were sought to explore FMNR benefits in resilience-building among the communities (Fig. 7). Adaptation and mitigation opportunities came out strongly with environmental conservation benefits leading, followed by enhanced availability of pasture for livestock and increased food security which aside from addressing the domestic household needs also offered better economic opportunities. Respondents confirmed that FMNR is an adaptable approach to land restoration especially in an ASAL context since it is easy to apply and inclusive (done by men, women, people living with disabilities, and children) and has high success rates,

Fig. 6 Analysis of the most affected gender in climate change risk scenarios
PERSONS AT RISK.

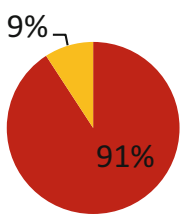

women and children at risk men at risk
Fig. 7 Opportunities FMNR provide for enhanced resilience

\section{OPPORTUNITIES IN FMNR FOR} RESILIENCE.

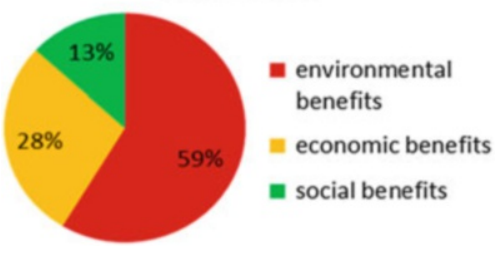


community bylaws, and regulation control in tree harvesting, thus reducing pressure caused by overharvesting of trees. Invasion of Prosopis juliflora (mathenge) in Marsabit is a menace, but FMNR management practices applied to this species have enabled better management. Increased access to high-value indigenous trees, e.g., wild fruits and Acacia pods, was cited by the pastoralists especially women as a critical feed for human and livestock especially during severe drought and for medicinal purposes. Often, women are the repository of extensive botanical knowledge since they know the traditional uses of many species. One woman says "Such trees are a mystery to us, without which we perish. Acacia tree pods and flowers can feed livestock for 10 months in scarcity of grass." Less migration of people and livestock is experienced where FMNR is practiced due to availability of pasture/fodder throughout the year. This reduced the burden of women being household heads during prolonged drought. They also mentioned the link between improved health and productivity of their livestock which ultimately addresses food security and economic empowerment since their livestock fetches higher market rates and increased milk and meat production offers nutrition needs as well as excess for markets. FMNR strengthens knowledge in tree-based value chains, thus enhancing diversification of livelihood opportunities from wood and non-wood forest products (NWFPs), e.g., trade in gums and resins, honey, gum arabic, firewood, acacia pods, wild fruits, etc. Respondents also brought out the FMNR social aspects in which cultural and religious attachments to specific species of trees enhanced their protection and management, e.g., there are species used during marriage, circumcision, and sacred events.

\section{What Are the Roles of Men and Women in Uptake of FMNR}

The objective explored the different roles played by men and women in the uptake of FMNR practice. This was based on the domestic chores undertaken by men and women in the family and community setup. It was evident that women are directly responsible for care and management of trees due to many derived benefits they accrue from the trees that enable them run their families. In all the mentioned roles of women, protection and use of the tree resources were most significant. Men, on the other hand, mainly offer administrative roles in control of the natural resource. Out of the nine roles played by men in uptake of the practice, five are mainly in management and control of use of the resources. Both men and women have equally economic interest role rates in the practice of FMNR. Trade in livestock, gum and resin, seeds, and wild fruit collection is done by both. Management and utilization of tree resources especially in large scale is reserved for men. It was interesting to note that development and enforcement of bylaws or regulations for environmental protection significantly sit on men (Fig. 8).

Generally, women often manage sheep and goats as they tend to be kept closer to the homestead. Women also tend to be left responsible for the home herd of cattle and camels when men take others on migration. As such, women's roles in livestock and environmental management should not be underestimated, and often their 


\begin{tabular}{|c|c|c|c|}
\hline No. & Men & Women & Both Men and Women \\
\hline 1. & $\begin{array}{l}\text { Decision making on management and } \\
\text { use of trees }\end{array}$ & Taking care of trees & Prunning and thinning of trees \\
\hline 2. & Control over the tree resources & $\begin{array}{l}\text { Feeding the family and small } \\
\text { stock from tree products }\end{array}$ & $\begin{array}{l}\text { Offer education on environmental } \\
\text { conservation }\end{array}$ \\
\hline 3. & $\begin{array}{l}\text { Administration of justice especially } \\
\text { for tree offenders }\end{array}$ & $\begin{array}{l}\text { Putting up shelter for the } \\
\text { family using tree branches }\end{array}$ & Harvesting of Wood and NWFPs \\
\hline 4. & Only men practise bee keeping & $\begin{array}{l}\text { Creating awareness and } \\
\text { trainings to other women on } \\
\text { FMNR }\end{array}$ & Trading in wood an NWFPs \\
\hline 5. & $\begin{array}{l}\text { Guide ceremonies in which specific } \\
\text { trees are used }\end{array}$ & $\begin{array}{l}\text { Reporting tree offences to } \\
\text { men/elders }\end{array}$ & \\
\hline 6. & $\begin{array}{l}\text { Educating young boys on importance } \\
\text { of taking care of the earth during } \\
\text { initiation ceremonies e.g. } \\
\text { circumcision }\end{array}$ & $\begin{array}{l}\text { Small scale harvesting of } \\
\text { Wood and NWFPs (firewood, } \\
\text { acacia pods, wild fruits, herbs, } \\
\text { gums and resins) }\end{array}$ & \\
\hline 7. & $\begin{array}{l}\text { Long and short distance grazing for } \\
\text { large herds especially during drought }\end{array}$ & $\begin{array}{l}\text { Trading in wood and NWFPs } \\
\text { to feed the family }\end{array}$ & \\
\hline 8. & $\begin{array}{l}\text { Large scale Harvesting of trees } \\
\text { especially mature/very old ones }\end{array}$ & $\begin{array}{l}\text { Short distance grazing } \\
\text { especially for small stock }\end{array}$ & \\
\hline 9. & $\begin{array}{l}\text { Developing bylaws/regulations for } \\
\text { tree management and use }\end{array}$ & $\begin{array}{l}\text { Protecting and watering of } \\
\text { trees e.g. the wildings }\end{array}$ & \\
\hline
\end{tabular}

Fig. 8 Roles of men and women in uptake of FMNR

knowledge on livestock as well as grazing areas, migration routes, and water points is rich. Women and men typically have different objectives for keeping animals, different authorities and responsibilities, and different abilities to access and use new information and improved technologies. These differences may lead them to have different priorities regarding investments in the adoption of new technologies and practices and/or different ideas about how best food and livelihood security can be attained through embracing FMNR.

\section{What Drives Women to Participate in or to Adopt FMNR}

From both FGD and KII interviews, FMNR ability to enhance access to immediate household basic needs, e.g., firewood, feeds (for human and livestock), building and fencing materials, and beddings, was cited as the most important driver to women participation in uptake of this practice (Fig. 9). Continued deforestation in Laisamis has led women walking long distances in search of firewood; one women reported walking $8 \mathrm{~h}$ (to and fro) to collect water and firewood from far off hills. Acacia pods offer nutritious feed for livestock especially during drought when pasture is limited, wild fruits have been a significant source of food in households, both seeds and wild fruits are also sold in the market, and women are mostly involved in this business. Alongside this, economic returns from sale of products from the environmental services accrued as a result of FMNR boosts women to participate in savings and loaning schemes, thus enabling them to expand and diversify their businesses/livelihood opportunities and increase their income levels. As they easily access basic immediate need through FMNR, women have more time to explore participating in other interventions like poultry keeping and kitchen gardening for nutrition and markets. One of the respondents noted that "Women 


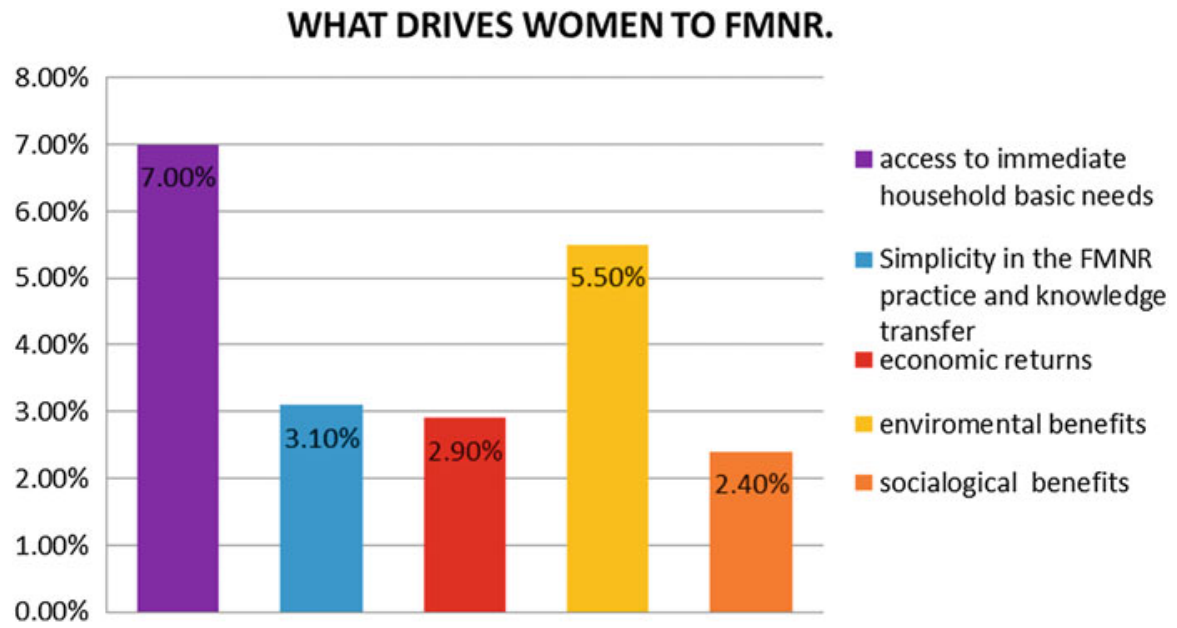

Fig. 9 Key drivers of women uptake and participation in FMNR

will go to great lengths to extract resources they need to take care of their families including entering dangerous insecure areas such as no-go zones which put them at risk of rape, kidnapping and killing." Improved health of livestock enhances the prices and increases milk production which is valuable to women. Ease in application and transferring of knowledge and practice of FMNR including its social benefits was ranked third in women drivers in uptake of FMNR. Participants affirmed the low-cost approach would best suit women since they are most vulnerable, and the more expensive an approach, the lesser application they would have of it. Majority of women in the region are illiterate; hence, the simplicity in the practice enhances women participation. Environmental benefits from FMNR were equally a factor since severely degraded landscapes are key threats to women because this deprives them access to basic ecosystem services. Marsabit is generally a dry place with high temperatures; FMNR increases tree cover that provides shade required by human and livestock. Women appreciated the importance of shade for resting and relaxing after daily chores. In some instances, goats have equally died due to prolonged exposure to very high temperatures, thus underpinning the importance of trees offering shade. Bare land exposes the community to excessive dust which further than contaminating food and causes eye and respiratory problems. Strong winds in the area have led to destruction of property; hence, trees play an important role as they serve as wind breaks.

\section{Key Barriers Affecting Women Participation in FMNR}

The main barrier limiting effective women participation in uptake of FMNR mentioned by all the respondents is excess workload on women which affects their concentration and consistency in rollout of FMNR since their attention is 


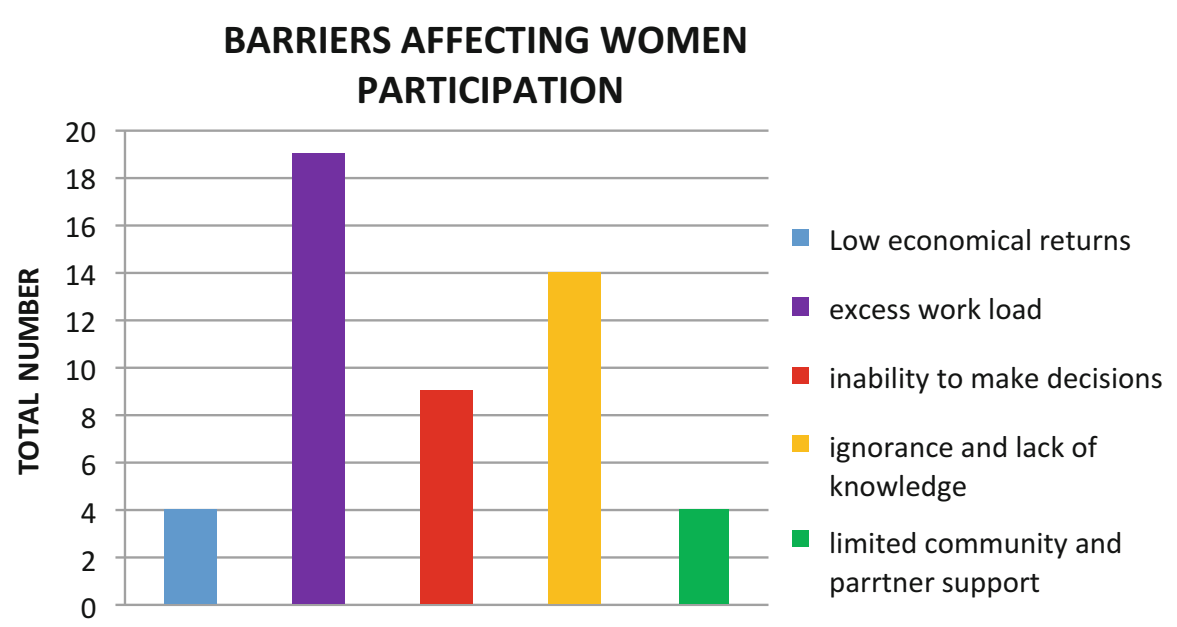

Fig. 10 Barriers affecting women participation in FMNR

diverged to addressing domestic chores and reproductive roles at household (Fig. 10). Severe drought and increased water stress necessitate this challenge overburdening women the more. Ignorance and lack of knowledge was cited as threat to uptake of this approach since it is likely to limit transfer of knowledge and skills. Most women in this community are illiterate, for instance, in women-only FGD, $90 \%$ of the respondents were only exposed to informal education and could only speak their local language, hence causing communication barriers in new knowledge transfers. Inability to make full decisions over management and utilization of tree resources as well as livestock that have direct linkage to success of FMNR was equally a challenge the women faced as observed by the respondents. Women's subordinate position in society, and their diminished access to information, education, and training, affects their participation in decision-making and public life. This is sometimes attributed to the cultural norms like overstocking by men depicting wealth and pride. Land ownership also rests on men; hence, women have limited power to make decisions on resources on land. Traditional institutions that offer guidance and leadership are mainly comprised of men; in fact, council of elders which is the highest traditional institution is purely composed of men. Women also need the security of knowing that they will have equal decisionmaking power in how resources and incomes from FMNR work will be used. This is especially important for women-headed households. Low economic returns and long-term benefits expected from trees and NWFPs minimize the interest of women in land restoration efforts including FMNR. The respondents acknowledged the many income sources from tree-based value chains, but the low market prices make the venture not worthwhile. For instance, they cited case of gums and resins which cost $200 / \mathrm{kg}$ in their locality, yet the same goes for 1000/= in the urban areas. This makes them feel exploited. Lack of organized market systems for the FMNR value chains limits women's return on the investments in the practice, thus 
derailing their efforts. Vastness of the area and limited transport means makes it even more difficult for knowledgeable people to create awareness of the approach due to logistical challenges. Minimal community and least concerted partner support to address this challenges derails passion among the existing women champions who strive to promote uptake of FMNR in the community.

\section{Recommendations for Enhancing Women Participation in FMNR Uptake}

Intense awareness and improved capacity for women to participate in FMNR was identified as most critical need in influencing their uptake of this approach (Fig. 11). This could be achieved through trainings, exposure to successful sites, and increased access to quality germplasm required by women. Gaps in effective monitoring and evaluation of projects have previously affected success of the projects; the respondents emphasized the need to have community-led monitoring, evaluation, and learning model for FMNR approach which are women-led, inclusive, and responsive. This will ensure women own this approach and integrate it in their daily activities. For instance, women are main beneficiaries of firewood; it's easy for them to include pruning and protecting of trees as they harvest firewood. The respondents also noted low involvement of community and partners in environmental conservation initiatives which then becomes a barrier to success of implementing this approach since it requires everyone. Drought management and increased water access is key in reducing pressure

\section{RECCOMENDATIONS.}

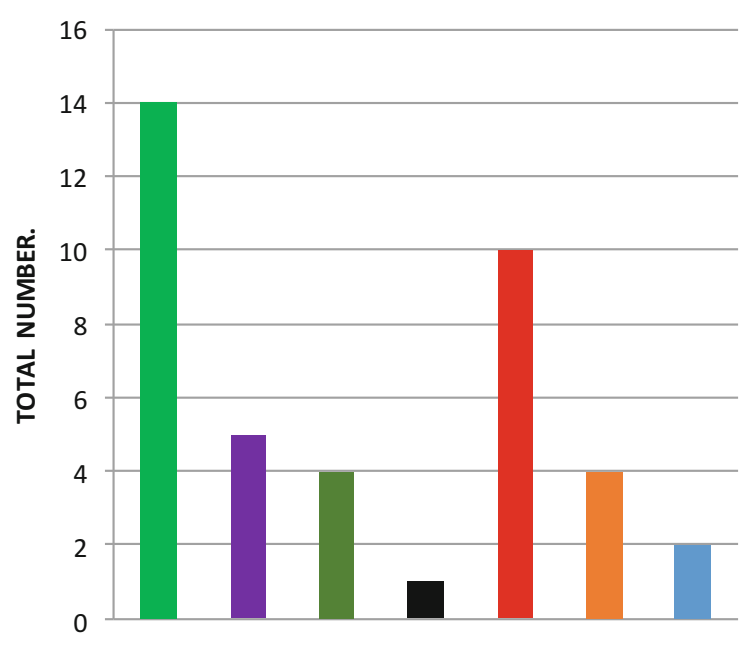

intense awareness and increased capacity to women on FMNR.

increased partners and communities support

participatory development and enforcement of by laws

drought management and water access

women led monitoring and evaluation.

market system strengthening on FMNR value chains

women empowerment in decision making and leadership.

Fig. 11 Key recommendations for women participation in FMNR 
women are exposed to in addressing household needs which would then give them time to get fully involved in FMNR activities. This continues to emphasize the need to invest more in adaptation and mitigation efforts to improve community resilience to climate change effects. More efforts are also required to ensure women meaningfully participate in decision-making and have leadership roles in natural resource management as they are the most at risk and have the ability to offer best solutions. In circumstances where women and men have equal access to productive resources, control over those resources is usually vested in men. Across all the above objectives, economic returns have been mentioned driver to investments by community in land restoration. While interrogating this further in the recommendations, respondents cited the need to strengthen the market systems and value chains along FMNR and other sustainable natural resource management approaches as this will attract more people to invest in the models. There are very many opportunities in FMNR that both address mitigation and adaptation which economic incentives would propel greatly. "Why can't private sector and research actors explore marketing or adding value to acacia pods from acacia tree that is proved to enhance milk production and health in goats and is the main livestock feed of all pastoral communities that take them from one drought season into the rainy seasons? The market for this product is disorganized hence no adequate return on investment, yet this can be big driver for pastoralists to bring back acacia trees on land which provide other multiple benefits" reiterates one of the respondents.

\section{Limitation of the Study}

While the case study has established significant findings and recommendations in enhancing women participation in uptake of FMNR for climate resilience, it's important to note that the limited duration in implementation of such findings may not yield to desired outcomes. The study also targeted a narrow geographical extent with small population applying the quantitative and quantitative data collection methods to derive the results; hence, the outcomes need to be understood within this scope. Intended, IMARA project evaluation in 2021 will additionally establish the contributions of these findings to the outcome of women participation in FMNR within Marsabit County. Additionally, it is important to note that in many communities living in ASALs, the status of women and girls is subordinate to that of men and boys. Key assets and resources, such as land, livestock, water, and cash, are generally controlled by older men rather than by women or youth, reflecting the subordinate position of women in society and the cultural limitations placed on their public role. The welfare of women and girls is also directly threatened by environmental problems, which increase the pressures of providing for the household, particularly water and fuelwood collection. Further studies are hence recommended in this field to bridge the gender gaps that continue to challenge women participation climate resilience initiatives or programs. 


\section{Conclusion}

About $80 \%$ of Kenyan women spend about $1-5$ h per day per household looking for fuelwood (p. vi), and in some rural locations (particularly in the ASALs), they spend 3-5.25 h a day collecting water (p. 20). Climate disasters can increase women's household responsibilities and cause disproportionate economic losses. During periods of drought, especially in the ASALs, women and children need to walk greater distances to fetch water and fuelwood. The household responsibilities of women can also increase, even more so if the able-bodied male members of a household leave in search of economic opportunities. Greater resource scarcity can also increase the likelihood of women and children being affected by conflict and violence. Women are at greater risk as well during periods of flood, when the occurrence of malaria, cholera, and dysentery - to which pregnant women and children are more vulnerable - can increase, particularly in areas where access to health care is inadequate. Despite women's multiple burdens, they have proved their capacity for effective collective action at the local level and shown that investment in their empowerment generates positive multiplier effects across communities in ways that improve human welfare.

IMARA program interventions on natural resource management for livelihoods seek to integrate gender and conflict prevention and prioritize sustainable, marketbased solutions to address the persistent challenges. The efforts will transform the lives of communities and households in the four target counties and revitalize/ preserve rangeland assets for the benefit of future generations especially women who are mostly affected by the negative impacts of climate change. According to the County Integrated Development Plans (CIDP) for Marsabit 2017, one of the key social problems in Marsabit County is high gender inequality as women and youth participation in development is low and there are few women and youth involved in leadership and decision-making; traditional and cultural practices are dominant. It is on this basis that the case study sought to investigate the factors affecting women participation in uptake of FMNR for climate resilience with the below summarized conclusion:

- There is evidence of risks associated with climate change linked to climate variability (drought, floods, high temperatures, disease outbreak), increased pressure on natural resources leading to resource-based conflicts, loss of livelihoods intensifying poverty, and social disintegrations causing lack of cohesion among communities. These increase vulnerabilities of communities, and $91 \%$ of the respondents noted that women and children as the most affected.

- Environmental, economic, and social benefits proved greatest opportunities FMNR has in increasing resilience of farmers to impacts of climate change.

- Women were cited to be more involved in the actual restoration and exploitation of the tree resources due to reproductive roles which are heavily dependent on sustainable landscapes. On the other hand, men are mainly into overall administration and management of the resources. This means women invest in what they have limited gains especially when there are huge returns. 
- Main drivers to women participation in FMNR included access to immediate practical needs, environmental benefits, simplicity and adaptability of the approach, and economic and social benefits. These are in order of priority.

- The greatest barrier threatening women participation in FMNR is excess work load on women in the household following limited efforts to address the burden of women especially in ASAL communities. Ignorance attributed to high illiteracy levels, low decision-making powers, low economic returns, and inadequate partner and community support limits women participation.

- Recommendations, intense gender-responsive FMNR campaigns, women-led monitoring, evaluation and learning, partner and community support, market systems strengthening for FMNR value chains, participatory development and enforcement of bylaws, women empowerment in leadership and decisionmaking, and finally drought management and increased water access (Figs. 12, $13,14,15,16$, and 17).

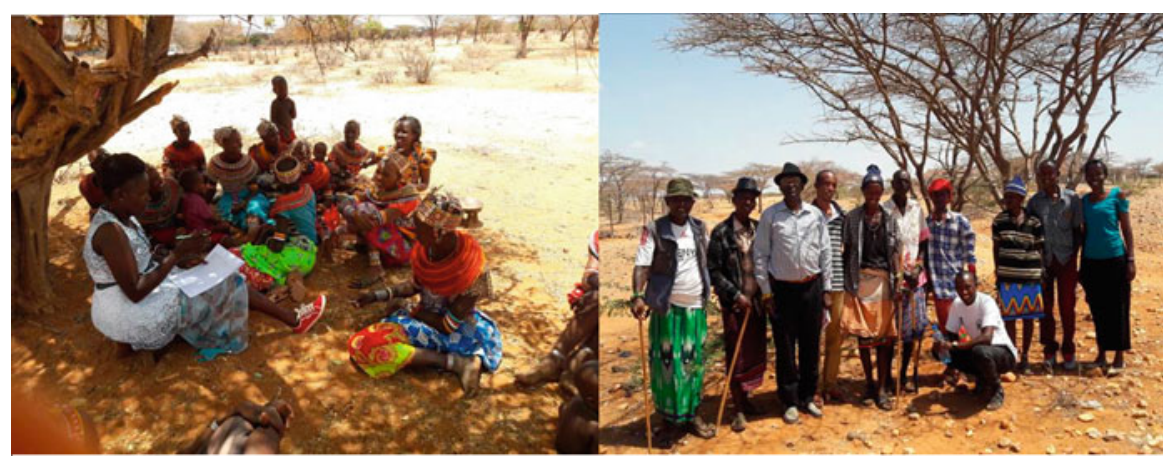

Fig. 12 FGD participants in sampled sessions. (Photo: Irene Ojuok)

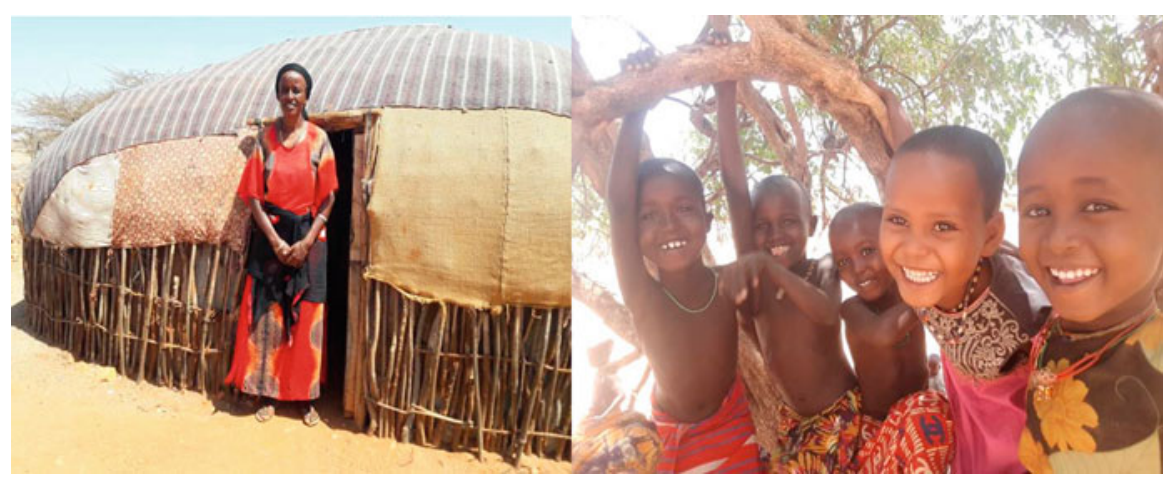

Fig. 13 Typical house in Laisamis constructed by woman and children enjoying on tree. (Photo: Irene Ojuok) 


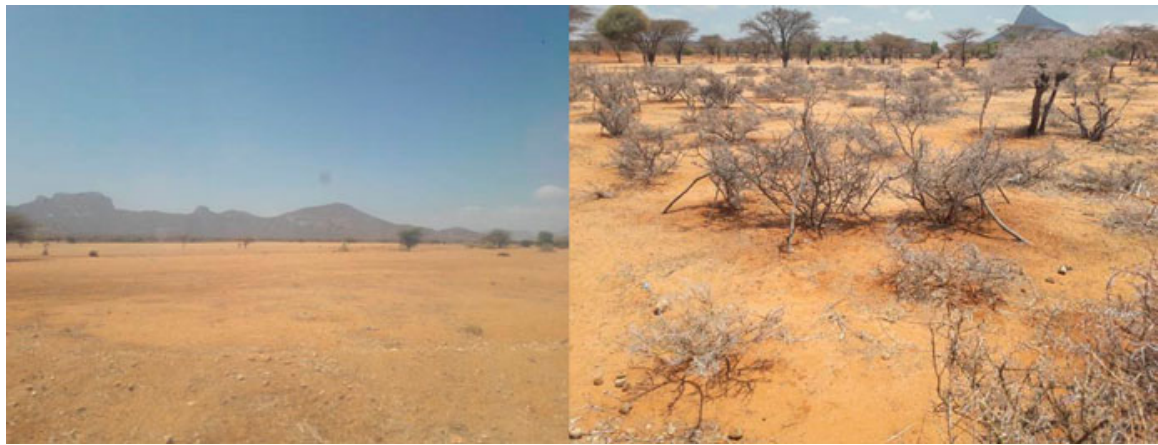

Fig. 14 Bare land that is severely degraded in Laisamis and another on FMNR practice. (Photo: Irene Ojuok)

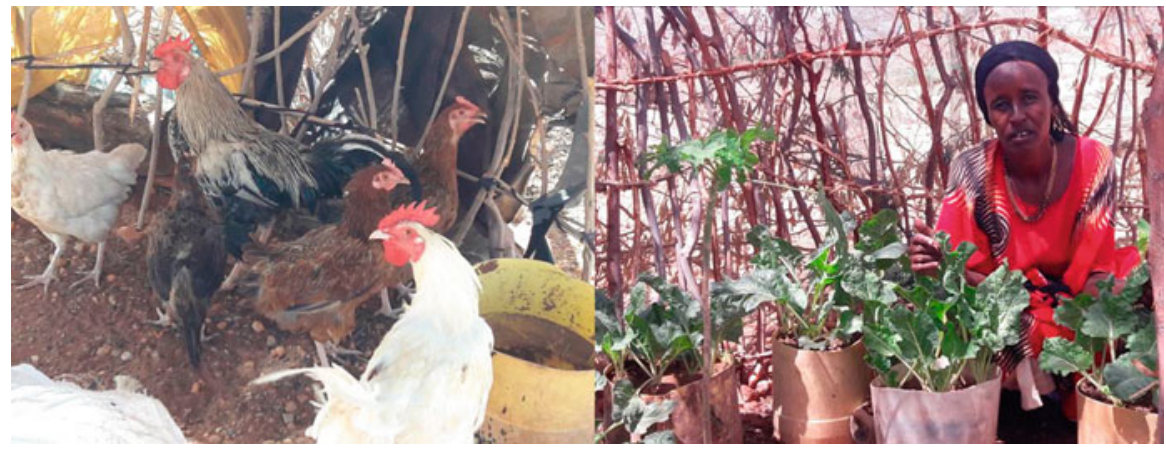

Fig. 15 Alternative livelihoods women engage in where FMNR is working with their support. (Photo: Irene Ojuok)

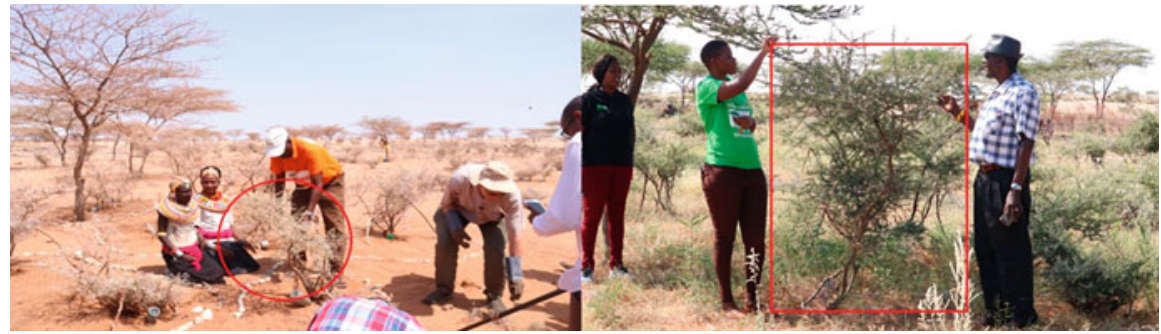

Fig. 16 On the left the "Tony Rinaudo" tree - as the community call it in July 2019. On the right, the same tree in January 2020, Iltepes women group FMNR site in Korr, Marsabit County. (Photo by Wesley Koskei WVK Communications Officer) 


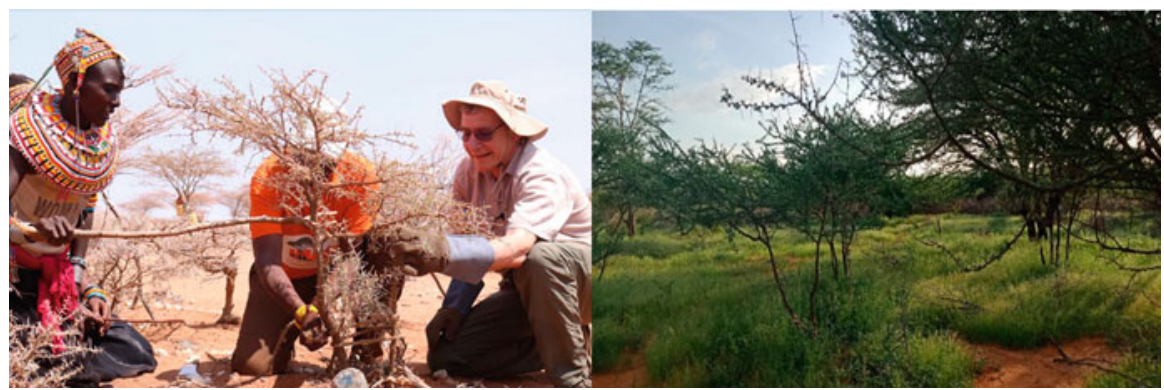

Fig. 17 Tony Rinaudo right livelihood laureate and founder of FMNR on the right with communities and World Vision staff in the field demonstrating FMNR practice, on the left is FMNR integrated with reseeding in Laisamis, Marsabit County. (Photo by Wesley Koskei WVK Communications officer)

Acknowledgments Special appreciation to SIDA for sponsoring this program through the International Training Program for Climate change Adaptation and Mitigation with support from World Vision Kenya and World Vision Australia FMNR Hub.

\section{References}

Coppock D et al (2013) Cross-border interaction spurs innovation and Hope among pastoral and agro-pastoral women of Ethiopia and Kenya. Rangelands 35(6):22-28

$\mathrm{https}$ :/www.google $\cdot \mathrm{com} / \mathrm{url}$ ? $\mathrm{sa}=\mathrm{t} \& \mathrm{rct}=\mathrm{j} \& \mathrm{q}=\& \mathrm{esrc}=\mathrm{s} \&$ source $=$ web $\& \mathrm{~cd}=8 \& \mathrm{cad}=\mathrm{rja} \& u a c t=8 \&$ ved=2ahUKEwjkhaiszrniAhWNERQKHcjXBHYQFjAHegQIBBAC\&url=http $\% 3 \mathrm{~A} \% 2 \mathrm{~F} \%$ 2Fwww.icpac.net\%2Fimages\%2Fpublications\%2Fadministrative\%2FICPAC_MAJOR_ ACHIEVEMENTS_2018.pdf\&usg=AOvVaw3xGTmRPrVJUfb4lFKd4nL4

https://www.the-star.co.ke/.../2019-04-24-seven-people-die-of-kala-azar-in-marsabitfmnrhub.com. au/wp-content/uploads/2013/09/Rinaudo-2007-Development-of-FMNR.pdf

https://www.unenvironment.org/news-and-stories/press-release/livelihoods-development-criticalpost-conflict-peacebuilding

ICPAC and the World Food Programme (WFP) Atlas (2017) Atlas of Climate Risk and Food Security in the Greater Horn of Africa Region

Nicholson SE (2001) Climatic and environmental change in Africa during the last two centuries. Clim Res 17:123-144

Republic of Kenya (ROK) (2000) National gender and development policy. Ministry of Gender, Sports, Culture and Social Services. Retrieved from http://bit.ly/P1CtN1

Open Access This chapter is licensed under the terms of the Creative Commons Attribution 4.0 International License (http://creativecommons.org/licenses/by/4.0/), which permits use, sharing, adaptation, distribution and reproduction in any medium or format, as long as you give appropriate credit to the original author(s) and the source, provide a link to the Creative Commons license and indicate if changes were made.

The images or other third party material in this chapter are included in the chapter's Creative Commons license, unless indicated otherwise in a credit line to the material. If material is not included in the chapter's Creative Commons license and your intended use is not permitted by statutory regulation or exceeds the permitted use, you will need to obtain permission directly from the copyright holder.

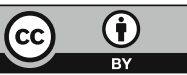

